Original Article

\title{
Awareness of Alcohol among Adolescents and Young Adults of Mangalore
}

\author{
Joswin Rakesh D'SA', Seemitha Shetty', Shahina V. ${ }^{1}$, Shashank Sahu', \\ Shifali Prabhakar', Rashmi Kundapur ${ }^{2} \&$ K. G. Kiran ${ }^{2}$ \\ ${ }^{1} \mathrm{M}$ BBS Students, ${ }^{2}$ Professor, Department of Community M edicine, \\ K.S. Hegde M edical Academy, Nitte University, M angalore, Karnataka, India. \\ Correspondence \\ Rashmi Kundapur \\ Professor, Department of Community M edicine, K.S. Hegde M edical Academy, \\ Nitte University, M angalore - 575 018, Karnataka, India. \\ M obile : +919880496567 E-mail : dr.rashmi.kundapur@gmail.com
}

\begin{abstract}
Introduction: Alcohol consumption is a major public health problem in most parts of the world responsible for 3.2 per cent of deaths (1.8 million). Prevalence of alcohol use in India is reported to be $21.4 \%$. The concern, is that there has been a rapid change in patterns and trends of alcohol use in India, chief among them is people are beginning to drink at ever-younger ages. Alcohol consumption of the students under the age of 18 years is markedly high which needs to be addressed.
\end{abstract}

Aims and Objectives: To assess the awareness of risk factors in alcohol consumption among adolescents and young adults.

Materialsand Method : M aterials used are-Questionnaire pertaining to the awareness of alcohol consumption.

Methodology : Assessment of awareness and knowledge of alcohol consumption was done by means of answering a pretested validated questionnaire with anonymity.

Results: According to the study done, $67.18 \%$ of students knew who consumed alcohol under the age of 18 . It was found, $28.03 \%$ of the subjects perceived that alcohol consumption started because of the urge to try something new.

Conclusion : A high majority of the students are aware of the underage drinking and risk factors associated with it.

Keywords: alcohol, awareness, adolescents

\section{Introduction}

Awareness of alcohol use and misuse on college campuses is not new. Alcohol consumption is a major public health problem in most parts of the world ${ }^{1}$, responsible for 3.2 per cent of deaths (1.8 million). WHO has estimated that there are about 2 billion people worldwide who consume alcoholic bevareges and 76.3 million with disorders arising out of harmful use of alcohol ${ }^{2}$. Prevalence of alcohol use in India is reported to be $21.4 \%$. Alcohol consumption has been steadily increasing in Access this article online Quick Response Code

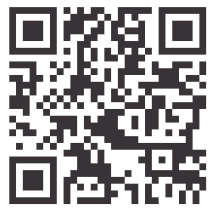
developing countries like India and decreasing in developed countries since the 1980s. ${ }^{1}$ Now-a-days there is increasing social acceptance of alcohol intake in various strata of society. The concern, say experts, is that there has been a rapid change in patterns and trends of alcohol use in India; chief among them being people beginning to drink at ever-younger ages.

Available research indicates that approximately $80 \%$ of college students drink and that half of student engage in heavy episo dic drinking. Alcohol being high in calories can have ill effects on the body. Regular drinking over the permissible amounts can lead to serious health problems, from liver damage to an increased risk of cancer or heart attacks. Students who engage in excessive drinking impact not just themselves but also the people around them. Fellow students experience second hand consequences ranging from disrupted study and sleep to physical and sexual assault. To address these serious consequences of alcohol consumption by college students, the National Advisory Council to the National Institute on Alcohol Abuse and Alcoholism (NIAAA) established the Task Force on 
College Drinking in $1998{ }^{3}$ With reference with that we tried to identify awareness level in students and their perception of risk factors.

\section{Objectives}

To assess the awareness of risk factors and among adolescents and young adults.

\section{Material Methods}

Community based cross-sectional study was conducted in different schools and colleges of M angalore. Taking 20\% awareness as baseline the sample size was calculated with $80 \%$ power of the study and $95 \%$ confidence interval, the sample size was calculated to be 400 with relative precision being $20 \%$ (power of study $80 \%$ ). Considering $20 \%$ non response, we considered to interview 480 students. Universal sampling in the colleges which were randomly selected from the college list was done for students. Our total sample was 487. A questionnaire consisting of questions that were based on the perception, knowledge of alcohol consumption and its consequences was prepared. Reliability and face validity of the questionnaire was done and linguistic validation was done. The questionnaire was to be filled anonymously. Sufficient time was given to the students to complete the questionnaire. Only students willing to participate with consent given were included. The data obtained were compiled in Microsoft excel and the results were tabulated in proportions and cross tables.

\section{Results}

The socio de4mographic data was almost similar with no major differences in the cohort. According to the study done $67.14 \%$ of students were aware of who consume alcohol under the age of 18 years (fig no: 1). Among them $58.08 \%$ of the subjects knew where these people go to drink. $30.09 \%$ to bars, $24.50 \%$ to pubs, $20 \%$ to parties and the rest to liquor shop (table no: 1) We found out that $58.56 \%$ of people perceive that alcohol consumption was started to try something new. $31.87 \%$ due to peer pressure, $28.28 \%$ due to stress and $8.36 \%$ people were influence by movies (fig no: 2). M ajority of the people perceived that alcohol consumption among these people was with their friends (79.02\%) rather than consuming it alone (8.60\%)

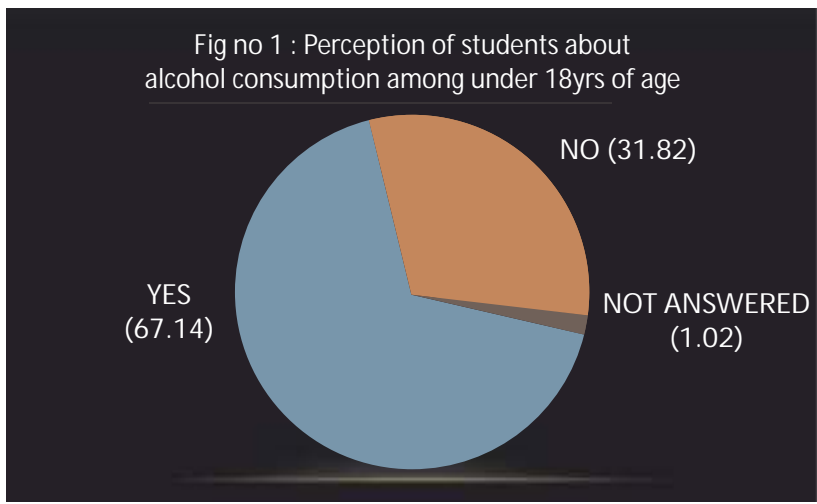

Fig no 2 : Perception of students about influencing factors leading alcohol consumption in adolescents

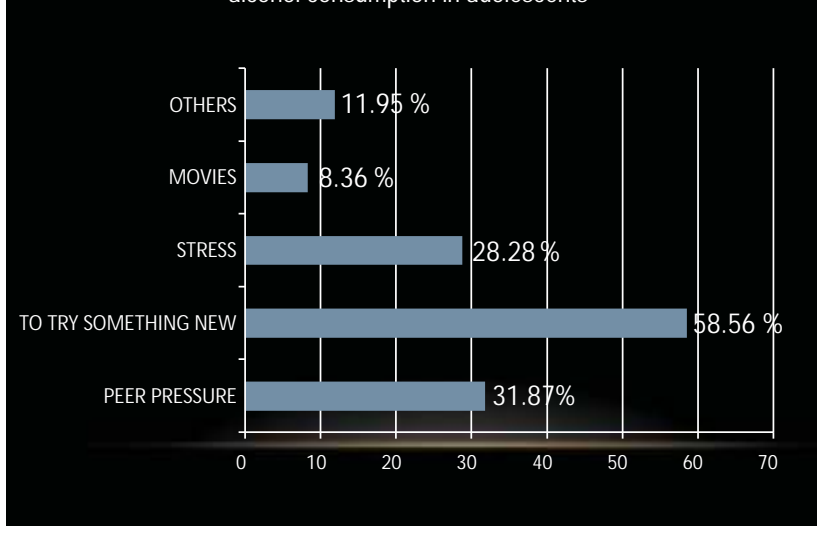

Table No.1 : Perception of Students about places were alcohol is available $(\mathrm{n}=280)$

(There is multiple responses so the percentages may not add up to 100)

\begin{tabular}{|c|c|c|}
\hline & NUMBER & PERCENTAGE \\
\hline BARS & 173 & $61.78 \%$ \\
\hline PUBS & 144 & $51.42 \%$ \\
\hline PARTIES & 115 & $41.07 \%$ \\
\hline LQUOR SHOPS & 61 & $21.78 \%$ \\
\hline OTHERS & 63 & $22.5 \%$ \\
\hline
\end{tabular}

\section{Discussion}

Alcoholism is a broad term for problems with alcohol, and is generally used to mean compulsive and uncontrolled consumption of alcoholic beverages, usually to the detriment of the drinker's health, personal relationships, and social standing. It is medically considered a disease, specifically an addictive illness. The World Health Organization (WHO) says there are at least 140 million alcoholics in the world; unfortunately, the majority of them are not treated. ${ }^{4} \mathrm{~A}$ US study estimated that about $30 \%$ of 
Americans report having an alcohol disorder at some time in their lives. ${ }^{5}$

Based on our study we have observed that knowledge about alcohol consumption under 18years of age was $67.14 \%$ and $31.82 \%$ had no idea about it.

We found that awareness about the availability of alcohol for students under 18years was $50.77 \%$ in our study compared to the study conducted in Australia in $2004^{5}$ where majority of the young people aged 12 - 17yrs i.e. $73 \%$ of them found it easy or very easy to get alcohol if they wanted some. Reported age of initiation of alcohol consumption has decreased over the last 5 decades. The age at which at least $50 \%$ of the survey responded, reported consuming a full serve of alcohol has reduced from approximately 19yrs to 15.5yrs in the Australian study ${ }^{5}$. In our study awareness was found to be good. Underage alcohol use remains a major public health and safety problem in India, creating serious personal, social,

\section{References}

1. Ramachandran V. The prevention of alcohol related problems. Indian J Psychiatry.1991;33:3-10.

2. World health Organisation (2008), Health Situation in the South - East Asia Region ,2001-2007.

3. Centre for Addiction and Mental Health (1998).Alcohol and Drug Prevention Programs for youth.

4 World health organisation (1986) .Tech .Res.Ser ., No.731.

5 Country Alcohol Problem Indicators 1986-1990.U.S. Alcohol Epidemiological Data Reference Manual, Volume 3 ,Fourth Edition, July 1994 ,NIH Publication No.94-3747. and economic consequences for adolescents, their families, communities, and the Nation as a whole. An emerging body of research on the effects of underage alcohol use on human maturation adds new urgency to the decade's long effort by the public and private sectors to prevent and reduce underage drinking.

\section{Limitations}

Our study captures only few factors regarding awareness of alcohol consumption, hence it cannot explain all the reasons for a student to take up a habit of consuming alcohol. This study do not have representative sample from all colleges.

\section{Conclusion}

A high majority of the students are aware of underage drinking and probable reasons for that in which something to try new exceeds which needs to be considered in school counceling sessions. 